University of Nebraska - Lincoln

DigitalCommons@University of Nebraska - Lincoln

9-29-2016

\title{
Case Study of Quantifying Energy Loss through Ceiling-Attic Recessed Lighting Fixtures through 3D Numerical Simulation
}

\author{
$\mathrm{Ri} \mathrm{Na}$ \\ University of Nebraska-Lincoln, rna2@unl.edu \\ Shengmao Lin \\ University of Nebraska-Lincoln, linshengmao@gmail.com \\ Zhigang Shen \\ University of Nebraska-Lincoln, shen@unl.edu \\ Linxia $\mathrm{Gu}$ \\ University of Nebraska-Lincoln, gul@fit.edu
}

Follow this and additional works at: https://digitalcommons.unl.edu/mechengfacpub

Part of the Architectural Engineering Commons, Construction Engineering Commons, Mechanics of Materials Commons, Nanoscience and Nanotechnology Commons, Other Engineering Science and Materials Commons, and the Other Mechanical Engineering Commons

$\mathrm{Na}$, Ri; Lin, Shengmao; Shen, Zhigang; and Gu, Linxia, "Case Study of Quantifying Energy Loss through Ceiling-Attic Recessed Lighting Fixtures through 3D Numerical Simulation" (2016). Mechanical \& Materials Engineering Faculty Publications. 172.

https://digitalcommons.unl.edu/mechengfacpub/172

This Article is brought to you for free and open access by the Mechanical \& Materials Engineering, Department of at DigitalCommons@University of Nebraska - Lincoln. It has been accepted for inclusion in Mechanical \& Materials Engineering Faculty Publications by an authorized administrator of DigitalCommons@University of Nebraska Lincoln. 


\title{
Case Study of Quantifying Energy Loss through Ceiling-Attic Recessed Lighting Fixtures through 3D Numerical Simulation
}

\author{
$\mathrm{Ri} \mathrm{Na},{ }^{1}$ Shengmao Lin, ${ }^{2}$ Zhigang Shen, ${ }^{3}$ and Linxia Gu${ }^{4}$ \\ 1 Graduate Assistant, Department of Construction Management, University of Nebraska-Lincoln, NH 122, Lincoln, NE 68588. \\ 2 Graduate Assistant, Department of Mechanical and Materials Engineering, University of Nebraska-Lincoln, NH 303B, Lincoln, NE 68588. \\ 3 Associate Professor, Department of Construction Management, University of Nebraska-Lincoln, W145 NH, Lincoln, NE 68588 (corresponding \\ author; email: shen@unl.edu ) \\ 4 Associate Professor, Department of Mechanical and Materials Engineering, University of Nebraska-Lincoln, W317.2 NH, Lincoln, NE 68588.
}

\begin{abstract}
Air leakage through recessed lighting fixtures has been identified as a common issue that causes extra energy consumption in residential buildings. However, few quantitative studies in this area were found. As such, a preliminary assessment of the magnitude of this type of energy loss was conducted by using three-dimensional (3D) transient computational fluid dynamics (CFD) models. A hypothetical layout of recessed lighting fixtures was designed with boundary conditions of four different seasons, which were obtained from recorded roof/attic temperature data sets. The results of the study indicate that leakage of recessed lighting fixtures could be a significant channel of energy loss in such attic-related residential buildings, especially in the summer and winter.
\end{abstract}

Keywords: energy loss, air leakage, recessed lighting fixtures, attic, computational fluid dynamics (CFD)

\section{Introduction}

Air filtration through building envelopes is a common factor that decreases the energy performance of residential buildings. Air filtration from recessed lighting fixtures (RLFs) is one of the identified leakage channels. To mitigate the issue in Washington State's building codes, all RLFs were required to be airtight (Washington State Building Code Council 2009). The code specified that RLF air-leakage rates were not to exceed $0.057 \mathrm{m3} / \mathrm{min}$ with a pressure difference of 75 Pascals, as a reference for RLF manufacturers. International Energy Conservation Code (IECC) and California also specified standards to guide the industry practice (ICC 2012; CBSC 2013). Although retrofit projects are not required to comply with all the new provisions, implementing these requirements in existing homes is recommended.

Leaking envelope areas can be detected by using blower-door tests and/or infrared camera techniques. However, such methods cannot provide a quantitative estimate for this type of energy loss, especially for RLFs mounted underneath ventilated attics, because of a lack of understanding of energy exchange and heat transfer under dynamic weather conditions. As a result, few quantitative studies on heating and/or cooling loss fromRLFs were found.

The goal of this research was to provide a quantitative evaluation of the impact of RLF air leakage on the energy consumption of attic-type homes through a case study. For simplicity, light bulbs in the studied RLFs are assumed to be off. When the light bulbs are on, the temperatures of the bulb can be $200-260^{\circ} \mathrm{C}$ (GEC 1984), which can accelerate or slow down the mass flow rate and make it a more complicated case.

In this paper, three-dimensional (3D) numerical models were used to calculate the energy load leakage amount under different seasonal conditions. The purpose of the numerical study is to provide an estimate of the heating and/or cooling loss due to air leakage from non-IC (insulation contact)-rated RLFs in a full year in the mixed humid zone in the United States. The selection of studying non-IC-rated RLFs is due to its large amount in U.S. housing inventory, especially in older houses. The temperature boundary conditions of attics used in this study were provided by the U.S. Department of Agriculture's (USDA) Forest Products Lab (Winandy et al. 2000). In this reference, roof temperature data from both Wisconsin and Mississippi were recorded. The reason for picking Mississippi was that, when compared with Wisconsin, the weather conditions in Mississippi are milder, so the case study in Mississippi can provide more generalized and typical results.

\section{Related Studies}

Airtightness is often a stringent requirement for building construction. In an investigation of the air-leakage problem in existing buildings, Persily (2004) evaluated 209 dwelling units, which represented $80 \%$ of the U.S. housing inventory, to find the distributions of residential infiltration rates. The results of the study indicate that in the United States, residential buildings have become more airtight since 1940. The impact of air leakage on heating and cooling loads is significant (Younes et al. 2012; Jokisalo et al. 2008), especially during winter and summer, when residential building envelope leakage can lead to increases of $30-40 \%$ of the heating loads and $10-15 \%$ of the cooling loads (Emmerich et al. 2005).

One common air-leakage area is from indoor space to attic space though the canister vents of RLFs, even when the lighting trim is properly sealed (Baker and Lugano 1999; Plympton et al. 2007; Savers 2006; Van der Meer 2002). Some serious leakage can even cause ice-dam issues (Armando and McCarthy 2000). In most studies, the potential air-leakage areas of the building were usually detected using an infrared thermographic technique during the blower-door 
test (Sherman and Dickerhoff 1998; Balaras and Argiriou 2002). However, very few quantitative studies that included evaluation of home energy losses through RLFs were found. Numerical methods such as computational fluid dynamics (CFD) became practical in simulating the airflow behavior in both residential and commercial applications (Younes et al. 2012) because of the significant improvement of computational technology from both hardware and software. Compared to experimental studies, CFD methods exhibited many advantages in solving air distribution and ventilation-related problems in the attic (Wang et al. 2012; Wang and Shen 2012a, b).

\section{Methodology}

\section{Numerical Model}

Surface and ambient temperatures from four different seasons were specified as the dynamic boundary conditions in a 3D transient CFD model in ANSYS Fluent 13.0. Although the 3D attic geometry model is hypothetical, the weather and temperature boundary conditions came from the recorded data by Mississippi Forest Products Laboratory in Starkville, Mississippi, in 1999. With these boundary conditions, energy exchange within this attic due to these RLFs was calculated.

The stableness of the attic ventilation (Wang et al. 2012) and the symmetrical nature in geometry and relevant boundary conditions enable us to use a quarter section of the model in the computational domain to reduce calculation time. Figure 1 shows the heat-transfer schematic of a ventilated attic due to stack effect only. Radiation and convection are considered in the simulations. For simplicity, without compromising the main focus, the attic is assumed to be occupied only by air, a Boussinesq fluid with a reference ambient air temperature To. The pressures at the soffit inlets and ridge vent outlets are assumed to be 0 gauge (which means no wind effect). As such, the airflow is assumed to be driven purely by buoyancy forces, which is also known as the stack effect. The inlet-location air is specified as turbulence intensity of $1 \%$ ( $\mathrm{Na}$ et al. 2014; Wang et al. 2012; Wang and Shen 2012a, b)

Figure 2 shows the geometric dimensions of the attic with the RLF layout. The simulated attic has a length, width, and height of 6,4 , and $1.677 \mathrm{~m}$, respectively. The roof dimensions reflect a $5 / 12$ roof pitch. There are nine RLFs in the simulated model, which is in accordance with the RFL installation guide from Home Depot (2015). All the recessed lighting cans are assumed to be non-IC rated tomeet the goal of this investigation. The dimensions of the cans were obtained from an actual non-IC-rated product bought from Home Depot. The canister has four $0.5 \times 2-\mathrm{cm}$ air vents surrounding the recessed lighting can (Figure 3) for heat dissipation generated by the light bulb when it is on. The diameter of each lighting can is $15 \mathrm{~cm}$. As a result, the ratio between canister vent areas versus total ceiling area equals to 0.68: 100. The roof areas and vertical wall areas are made of $3-\mathrm{cm}-$ thick plywood. The ceiling is made of $0.27-\mathrm{cm}$-thick gypsum board covered with 15-cm-thick fiber insulation ( $\mathrm{Na}$ et al. 2014).

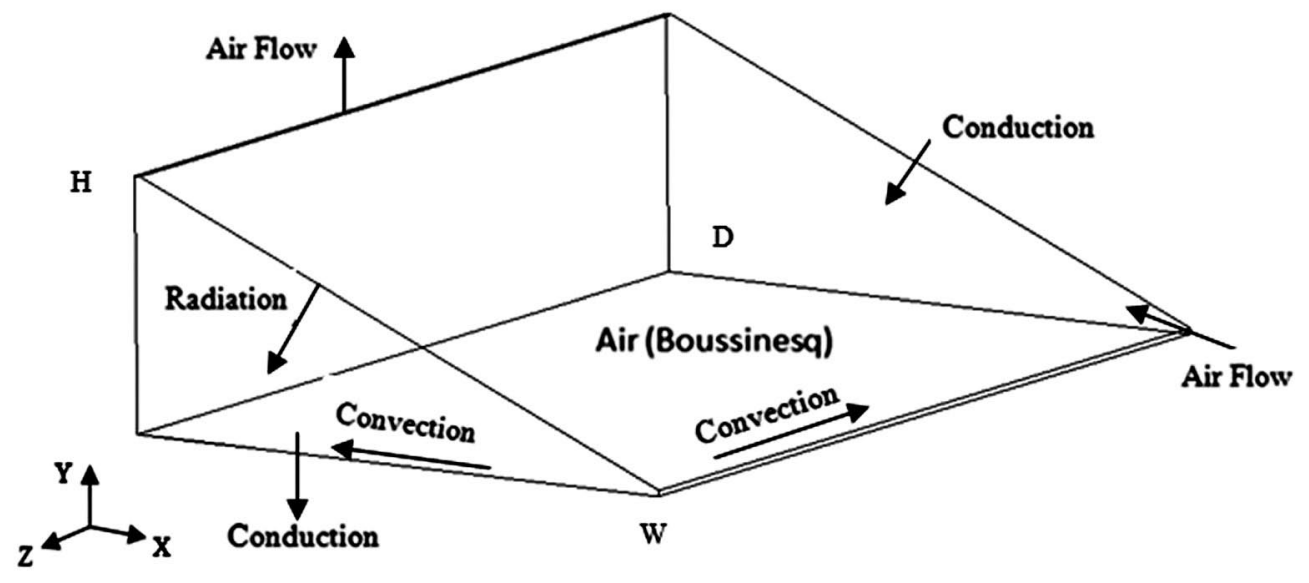

Figure 1. Schematic of the heat-transfer mechanisms in the ventilated attic
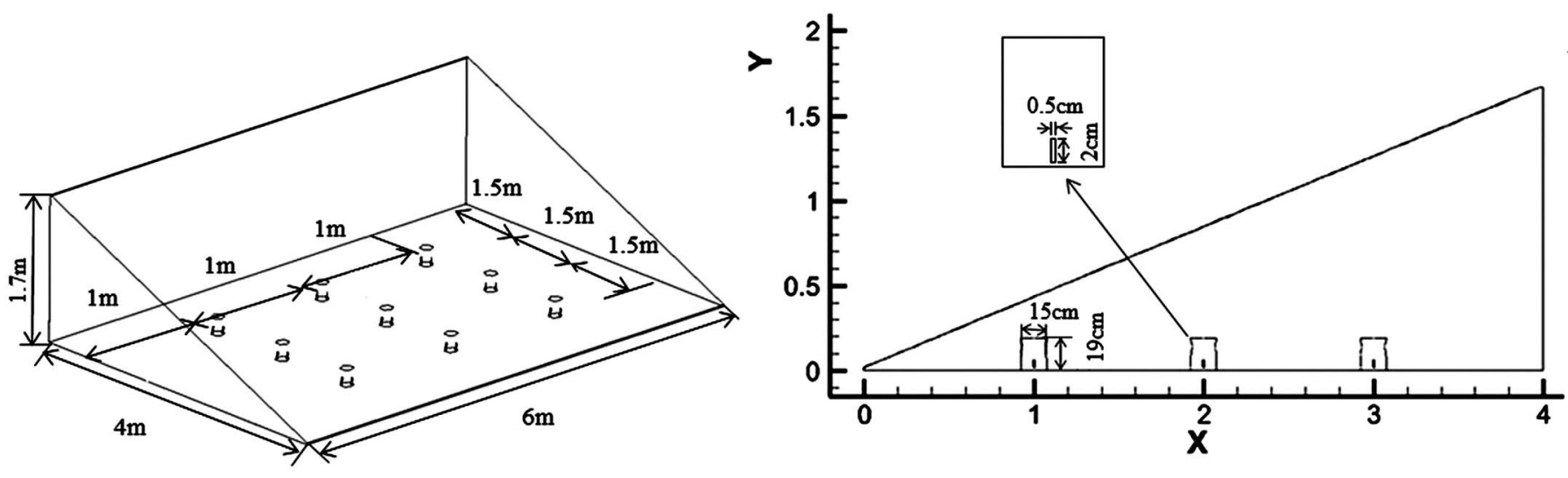

Figure 2. Geometry of an attic with recessed lighting 


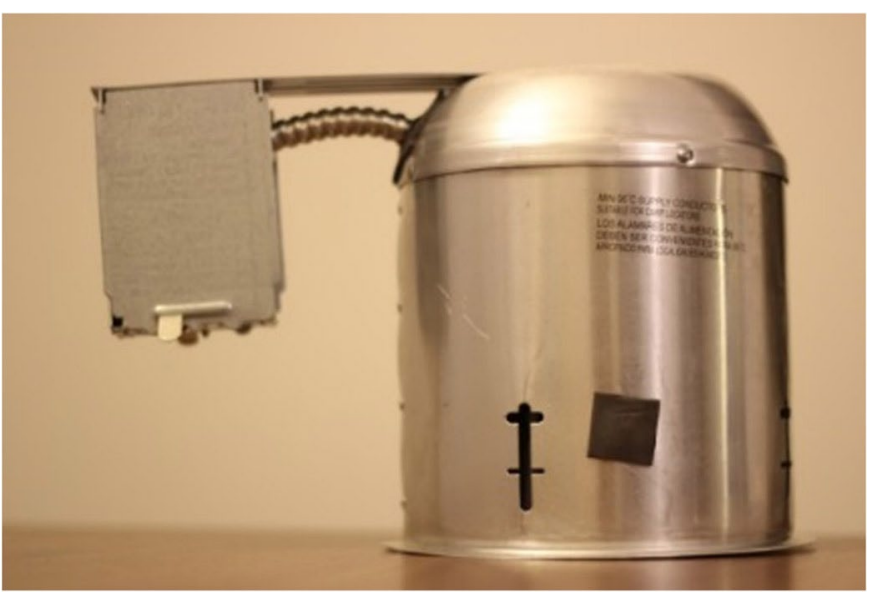

Figure 3. Sample recessed lighting can

Natural ventilation with a ventilation ratio of $1 / 200$ is assumed (Wang et al. 2012). "Ventilation ratio refers to the net free area, such as soffit and ridge vent regions, divided by the deck area of the attic" (Na et al. 2014). The thermal resistance of the insulation layer and exterior surface materials' emissivity are shown in Table 1. The conduction heat transfer is considered on every bounding surface. In addition, convection boundary conditions are applied to walls, ceilings, and roofs. Face-to-face radiation boundary conditions are applied to roofs and walls.

In the attic space, every surface exchanges heat with every other surface through radiation. The energy reflected from surface $k$ is

$$
q_{\text {out }, k}=\varepsilon_{k} \sigma T_{k}^{4}+\left(1-\varepsilon_{k}\right) q_{\mathrm{in}, k}
$$

where $q_{\text {out }, k}$ is the energy flux leaving the surface; $\varepsilon_{k}$ is the emissivity; $\sigma$ is Boltzmann's constant; $q_{\text {in }, k}$ is the energy flux incident on the surface from the surroundings" (Na et al. 2014).

The amount of incident energy upon a surface from another surface is the direct function of the surface-to-surface view factor. The view factor $F_{i j}$ between two finite surfaces $i$ and $j$ is given by:

$$
F_{i j}=\frac{1}{A_{i}} \int_{A i} \int_{A j} \frac{\cos \theta_{i} \cos \theta_{j}}{\pi r^{2}} \delta_{i j} \delta A_{i} \delta A_{j}
$$

where $\delta_{i j}$ is determined by the visibility of $\delta A_{j}$ to $\delta A_{i \cdot} \delta_{i j}=1$ if $\delta A_{j}$ is visible to $\delta A_{i}$ and 0 otherwise ( $\mathrm{Na}$ et al. 2014). From the view factor reciprocity relationship, the energy-flux incident to the roof surfaces from the others can be expressed as

$$
q_{\mathrm{in}, k}=\sum_{j=1}^{N} F_{k j} q_{\mathrm{out}, j}
$$

Therefore,

$$
q_{\text {out }, k}=\varepsilon_{k} \sigma T_{k}^{4}+\left(1-\varepsilon_{k}\right) \sum_{j=1}^{N} F_{k j} q_{\text {out }, j}
$$

The airflow dynamics was governed by the momentum and mass conservation equations as follows:
Table 1. Boundary Conditions

\begin{tabular}{lll}
\hline Element & Thermal conductivity $\left(\mathrm{W} / \mathrm{m}^{2} \cdot \mathrm{K}\right)$ & Emissivity \\
\hline Roof & $\mathrm{R}-1.2(4.733)$ & 0.85 \\
Vertical wall & $\mathrm{R}-1.2(4.733)$ & 0.85 \\
Ceiling & $\mathrm{R}-20(0.284)$ & - \\
\hline
\end{tabular}

$$
\begin{gathered}
\text { Mass: } \quad \rho_{f} \Delta \cdot v=0 \\
\text { Momentum: } \quad \rho_{f} \frac{\partial v}{\partial t}+\rho_{f}\left[\left(v-d_{f}\right) \cdot \nabla\right] v=\nabla \cdot \tau_{f}+f_{f}^{B}
\end{gathered}
$$

"where $\rho_{f}$ is the fluid density, $\tau_{f}$ is the fluid stress tensor, $f_{f}^{B}$ are the body forces per unit volume, $v$ is the fluid velocity vector, $d_{f}$. is the moving coordinate velocity and $v-d_{f}$ is the relative velocity of the fluid with respect to the moving coordinate velocity" ( $\mathrm{Na}$ et al. 2014).

"The turbulence model employed in this study is $k-k l-\omega$ transition model (Walters and Cokljat 2008), which is an eddy-viscosity turbulence model based on the $k-\omega$ framework and includes laminar kinetic energy to represent the pretransitional fluctuations in boundary layers. The pressure and velocity coupling is solved by the coupled algorithm with the second order scheme of pressure. The third-order monotonic upstream-centered scheme for conservation laws (MUSL) is adopted for the discretization of all the variables other than pressure" ( $\mathrm{Na}$ et al. 2014). The $k-k l-\omega$ model was validated in similar attic settings by Wang et al. (2012).

The 3D model consists of approximately $200,000-600,000$ hex elements owing to the geometry size difference in each model. Hex is a cube mesh element, which is one of the most common mesh types in CFD analysis. Compared with other mesh types, such as tetrahedron, pyramid, and triangular prism, hex meshes require the highest computing cost but can provide the most accurate solutions (Duan et al. 2015). A refined boundary layer that consists of four layer elements is added at the bottom side of the roof. Calculations are initiated from 0 velocity and uniform temperature, with a timestep size of $1 \mathrm{~s}$ with 20 iterations in each step. A negligible difference was found when decreasing the time step to $0.5 \mathrm{~s}$ or with 40 iterations in each time step. The simulation converges with energy residual less than $1 \times 10^{-6}$ after approximately 3,500 time steps.

\section{Roof Temperature Collection}

The roof and ambient temperatures used in this study came from the recorded temperature data found by Winandy et al. (2000). Starkville belongs to the mixed-humid zone according to Building America climate zone divisions (Baechler et al. 2010).

Because of the long computational time, temperature data of only one typical day from each season were taken from recoded data sets. According to the climate records (Winandy et al. 2000), the coldest and hottest days in the selected year were found in January and July. Temperature conditions in these two months were selected to reflect winter and summer seasons in the region.

Temperature conditions in April and October were used to represent the spring and fall seasons. The variations of hourly temperature data of the four months are calculated in each season. The leastdaily- total variances are identified in each month. In each season, the dates that had daily temperatures closest to their corresponding monthly average were identified as January 7, April 28, July 10 , and October 29. As such, these four days are chosen to represent a typical day of the corresponding season. The temperature profiles of roof and ambient temperatures in the four days are used as the boundary conditions in the 3D CFD model. 
To find the time series approximate functions of the 24-h temperature profiles, the recorded roof and ambient temperature data "in the four selected days are fitted into a four-series Gaussian function, respectively, as listed in Equation (7), using the nonlinear least square fit method in MATLAB. The R-squares are all above 0.99, which indicate a good match between the recorded data and the fitted data. The fitted functions then were applied to the 3D model as the boundary conditions.

$f(x)=a_{1} e^{\left[\frac{\left(x-b_{1}\right)}{c_{1}}\right]^{2}}+a_{2} e^{\left[\frac{\left(x-b_{2}\right)}{c_{2}}\right]^{2}}+a_{3} e^{\left[\frac{\left(x-b_{3}\right)}{c_{3}}\right]^{2}}+a_{4} e^{\left[\frac{\left(x-b_{4}\right)}{c_{4}}\right]^{2}}$ (7)

where $x=$ time (s). $x$ starts from $14,400 \mathrm{~s}$ for each condition to allow four hours (before the start of each day) to be taken into account in the function fitting to improve the accuracy of the results; the fitted temperature $f(x)$ is in terms of " $K^{\prime \prime}$; and constants $a_{1}, a_{2^{\prime}} a_{3^{\prime}}, b_{1}, b_{2^{\prime}}, b_{3^{\prime}}$ $c_{1}, c_{2}, c_{3}, a, b$, and $c$ represent amplitude, centroid, and peak width, respectively, of the temperature curves" (Na et al. 2014). The results of the fitting are shown in Table 2 .

\section{Data Processing}

The mass flow rates of the RLFs and the heat-transfer rates of the ceiling area are calculated in CFD on the basis of Eqs. (5) and (6). The energy-loss rate of RLFs is estimated using Eqs. (8) and (9).

$$
\begin{gathered}
m=V_{m} \Delta t \\
q_{r}=\frac{c m \Delta T}{\Delta t}=c V_{m} \Delta T_{1}
\end{gathered}
$$

"where $c$ is the specific heat capacity constant $(\mathrm{J} / \mathrm{kg} \cdot \mathrm{K})$, which is equal to 1,006 for the air; $m$ is mass $(\mathrm{kg}) ;$ and $\Delta T_{1}$ is the indoor and outdoor air temperature difference $(K)$; indoor air temperature equals $293 \mathrm{~K}$ in the winter, $297 \mathrm{~K}$ in the summer, and $295 \mathrm{~K}$ in the spring and fall; $\Delta t$ is the duration of the energy loss; $V_{m}$ is the mass flow rate of air $(\mathrm{kg} / \mathrm{s})$; and $q_{r}$ is the heat-transfer rate of the RLFs $(\mathrm{W}) "$ (Na et al. 2014).

The conduction heat-transfer rate of the ceiling is calculated using Equation (10).

$$
q_{c}=h_{c} A \Delta T_{2}
$$

where $q_{c}$ is the ceiling heat-transfer rate $(\mathrm{W}) ; A$ is the ceiling area $\left(\mathrm{m}^{2}\right) ; h_{c}$ is the conductive heat-transfer coefficient as $0.284\left(\mathrm{~W} / \mathrm{m}^{2} \cdot \mathrm{K}\right)$; and $\Delta T_{2}$ is the temperature difference between the surface and the bulk fluid (K).

The energy loss from the RLFs and the ceiling is estimated using Eqs. (11) and (12).

$$
\begin{aligned}
& Q_{r}=q_{r} \times \Delta t \\
& Q_{c}=q_{c} \times \Delta t
\end{aligned}
$$

where $Q_{r}=$ energy loss from the RLFs $(\mathrm{KJ})$; and $Q_{c}=$ energy loss from the ceiling $(\mathrm{KJ})$.

The percentage of energy loss from the RLFs can be calculated by the following:

$$
\mathrm{RLF} \%=\frac{Q_{r}}{Q_{c}+Q_{r}}
$$

\section{Results and Discussion}

Different daily (24-h) energy-loss patterns are found in each of the four seasons. In the following paragraphs, each pattern in each season is discussed in more detail.

\section{Winter Conditions}

The bottom-side temperature of the ceiling is assumed as a constant $(293 \mathrm{~K})$, representing space with heating equipment, while the topside temperature is calculated by both radiation and air convection. During nighttime [Figure 4(a)], the roof temperature is very similar to the outdoor temperature, which brings ignorable radiation effects. "Thus, the temperature of the upper side of the ceiling is dominated by air convection. Since the difference between the outdoor and indoor air temperature is larger during night, the energy loss from the ceiling is at high level [Figure 4(c)]. In the daytime, as the roof temperature becomes higher than the outdoor temperature [Figure 4(a)], the radiation from the roof gradually increases. In the meantime, the difference between the indoor air and outdoor air temperature decreases. As a result, the energy loss from the ceiling decreases in the daytime" ( $\mathrm{Na}$ et al. 2014).

The energy loss from the RLFs is determined by the mass flow

\begin{tabular}{|c|c|c|c|c|c|c|c|c|}
\hline$C$ & \multicolumn{2}{|c|}{ January 7} & \multicolumn{2}{|c|}{ April 28} & \multicolumn{2}{|c|}{ July 10} & \multicolumn{2}{|c|}{ October 29} \\
\hline$a_{1}$ & 13.51 & 252 & 10.87 & 301.4 & 51.63 & 196.8 & 22.69 & 289.8 \\
\hline$a_{3}$ & 35.8 & 98.37 & 13.7 & 49.89 & -34.07 & 228 & 35.13 & 14.13 \\
\hline$a_{4}$ & 4.43 & 230.1 & 39.41 & 9.165 & 271.4 & 53.88 & 42.58 & 132.6 \\
\hline$b_{3}$ & $-16,730$ & 18,630 & 94,350 & 111,300 & 102,400 & 53,250 & 105,600 & 22,340 \\
\hline$b_{4}$ & 26,920 & 116,900 & 61,620 & 24,230 & $-8,697$ & 109,000 & 64,120 & 115,500 \\
\hline$c_{1}$ & 10,750 & 44,380 & 4,127 & 90,510 & 18,140 & 35,930 & 8,581 & 56,780 \\
\hline$c_{2}$ & 250,200 & 27,790 & $6,614,000$ & 31,750 & 73,740 & 44,910 & 371,500 & 40,910 \\
\hline$c_{3}$ & 35,550 & 25,010 & 24,550 & 21,120 & 23,980 & 42,200 & 33,230 & 15,760 \\
\hline$c_{4}$ & 20,280 & 39,890 & 14,190 & 14,000 & 72,400 & 13,210 & 13,000 & 26,740 \\
\hline
\end{tabular}
rate of the air leakage [Eqs. (5) and (6)] and the difference between the outdoor and indoor air temperatures. As Figure 4(b) shows, the rise of the roof temperature in the daytime intensifies the soffit-ridge ventilation, which causes the increase of the mass flow rate through

Table 2. Value of Constants in the Fitted Temperature Functions 

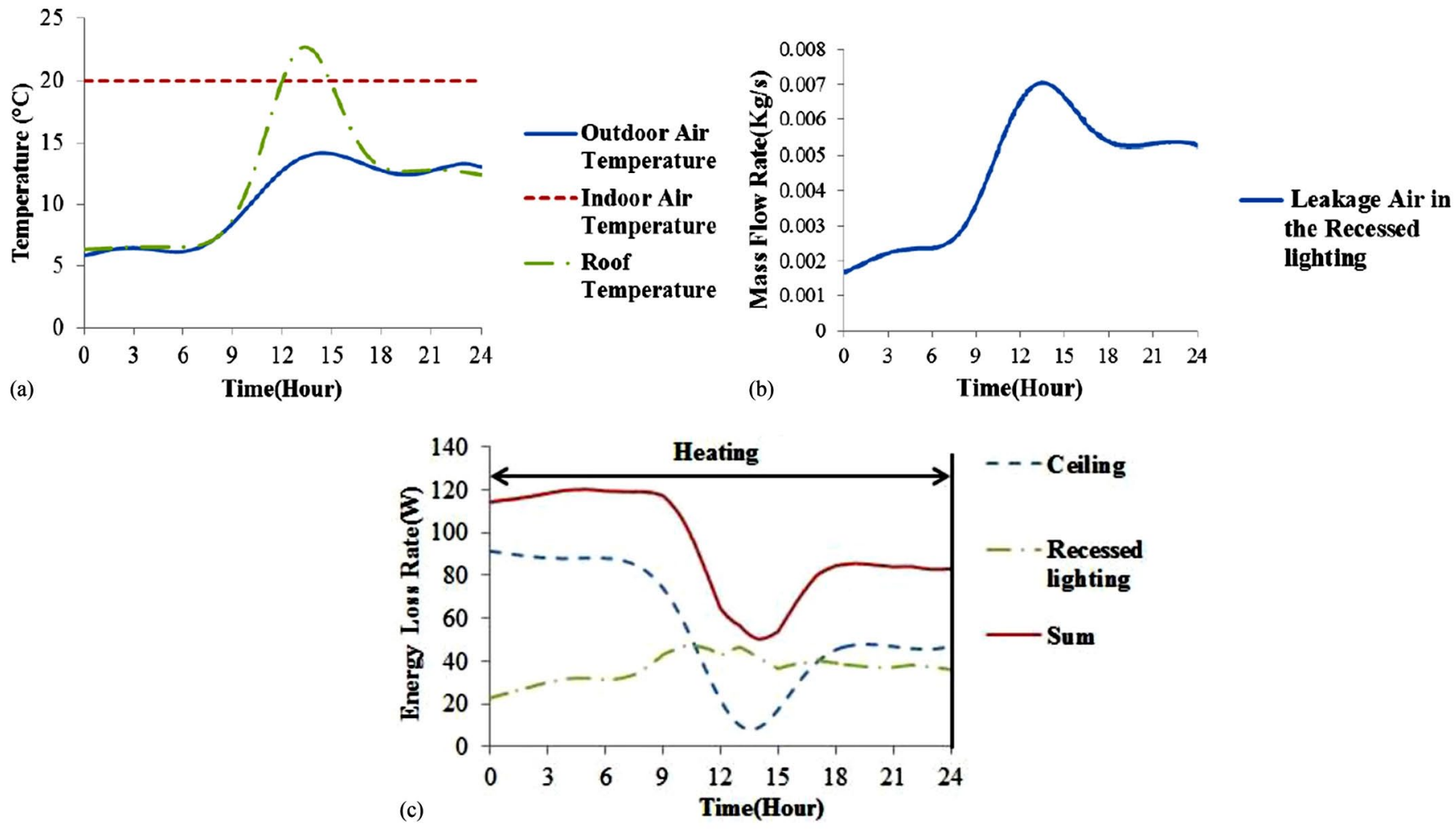

Figure 4. (a) Temperature data, (b) mass flow rate of the leakage air in recessed lighting, and (c) 24-h attic energy loss on January 7, 1999

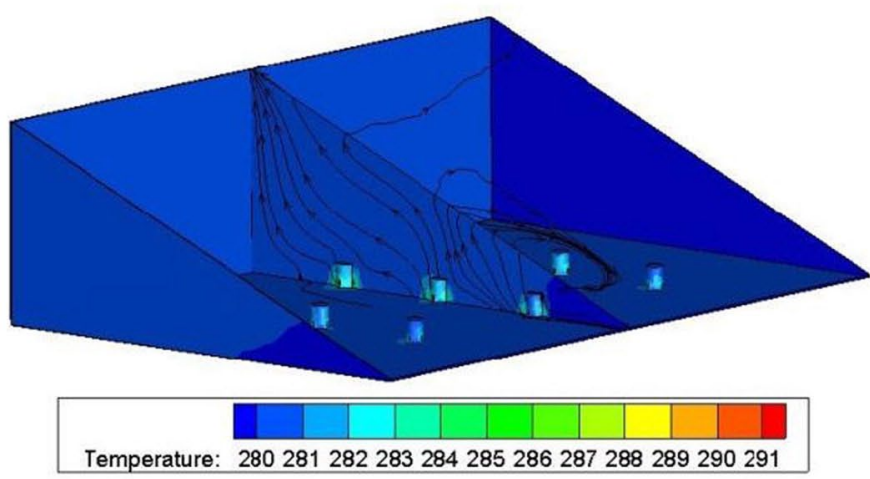

(a)

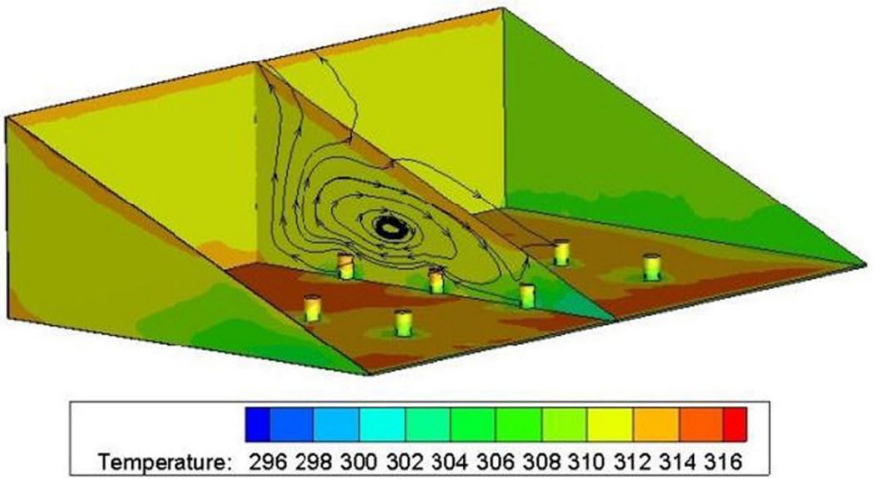

(b)

Figure 5. Streamlines and contours of temperature in the (a) nighttime and (b) daytime on January 7, 1999

RLFs. As a result, the energy loss increases compared to that in the nighttime regardless of the reduced temperature difference in the daytime. Similarly, when the light bulbs are on, the high temperature of the bulb surface could also intensify the leakage mass flow rate and make it an even worse case.

\section{Spring Conditions}

Compared to January when the indoor air enters through the bottom of the canister, rises up, and goes out from the ridge vent (Figure 5), the spring-season airflow is in an opposite direction in the nighttime [Figure 6(a)]. In the spring season, both the heating load and the cooling load are needed to keep the indoor air temperature constant [Figure 6(c)]. Because the outdoor air and roof temperature difference is relatively small, the energy-loss amount through RLFs is small during this time compared with that in the winter.

When the light bulbs are on, the mass flow rate from the RLFs is accelerated during the daytime, which results in an increase of energy loss. During the nighttime, the outside temperature is colder than the indoor temperature, and the warm temperature of the bulb can slow down the infiltration of the colder ambient air through the RLFs, which can reduce the energy loss.

In the daytime, when the roof temperature becomes greater than the ambient temperature, the roof becomes a heating source for the air in the attic. This makes the indoor air rise and leak into the attic, as shown in Figure 7. Compared to January, the April through-ceiling energy loss accounts for a relatively larger portion in the daytime [Figure $6(\mathrm{c})$ ], which is due to the relatively larger difference between indoor and outdoor temperatures [Figure 6(a)]. 

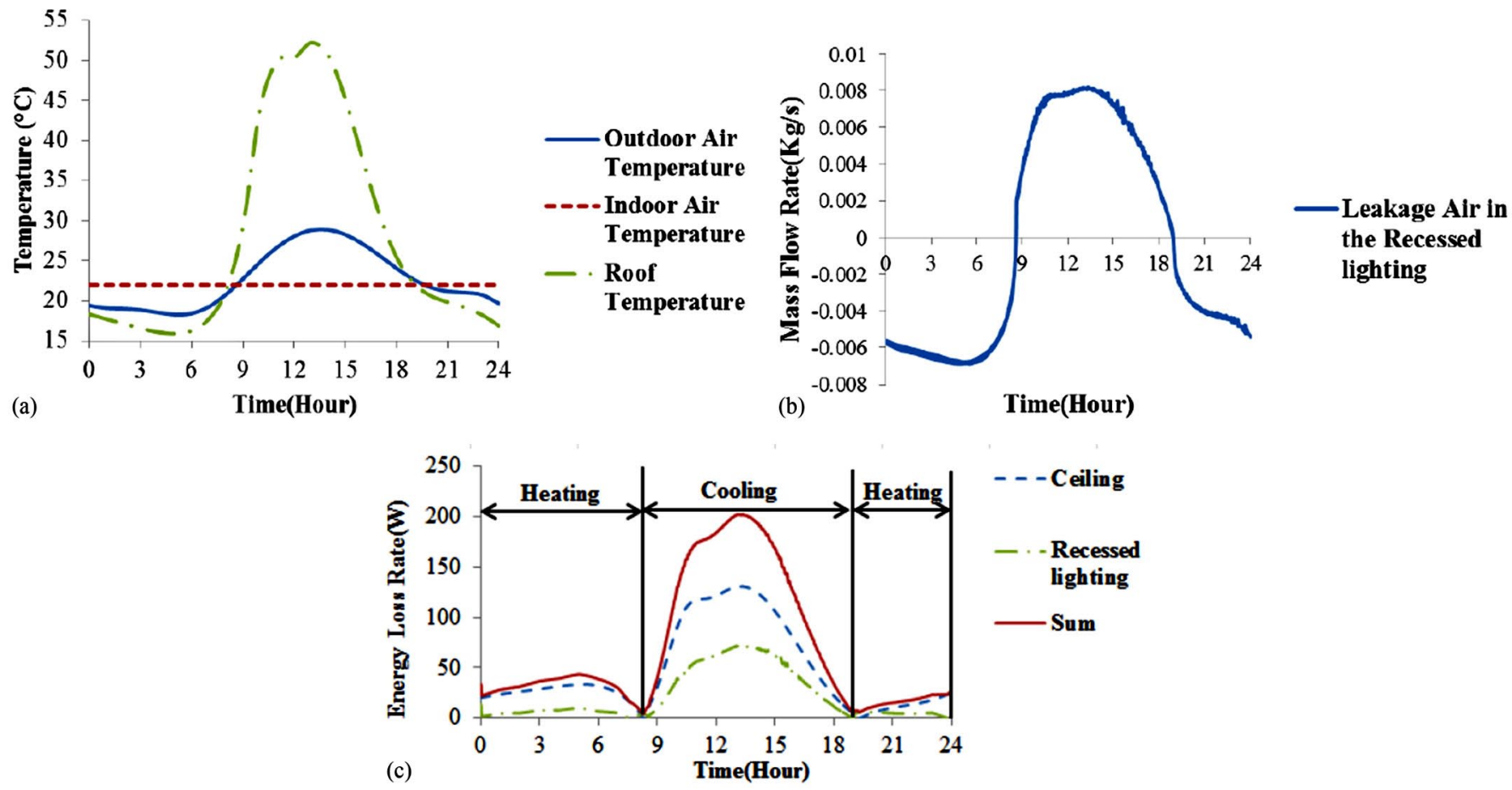

Figure 6. (a) Temperature data, (b) mass flow rate of the leakage air in recessed lighting, and (c) 24-h attic energy loss on April 28, 1999

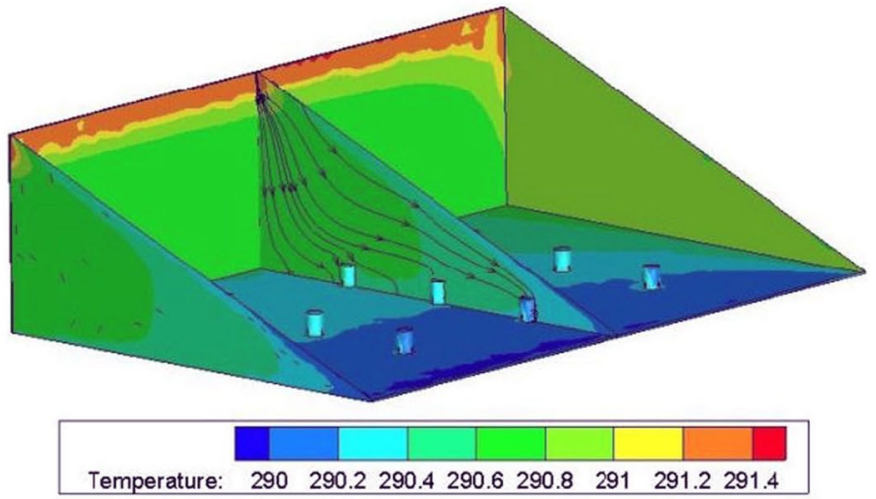

(a)

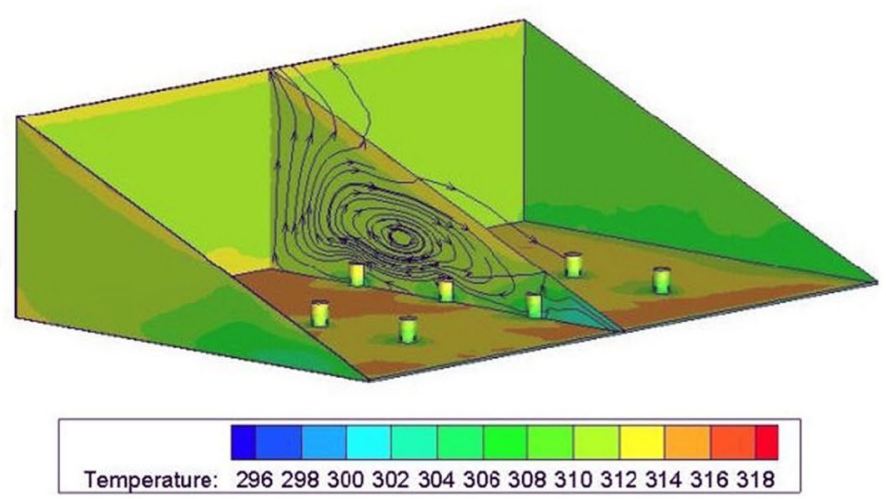

(b)

Figure 7. Streamlines and contours of temperature in the (a) nighttime and (b) daytime on April 28, 1999

\section{Summer Conditions}

Despite the similar energy-loss pattern to the spring season, the summer energy-loss rate for both ceiling and RLFs becomes larger (Figure 8) (Na et al. 2014).

Similar to the spring case, when the light bulbs are on, the warm temperature of the bulb can slow down the airflow (Figure 9) through the RLFs during the nighttime because of the opposite direction of the airflow and, thus, could reduce the energy loss, which is a better case scenario. During the daytime, the warm temperature of the light bulb can intensify the chimney effect and, thus, increase the energy loss, which is a worse-case scenario.

\section{Fall Conditions}

Figure 10(c) shows the larger fluctuating pattern of the energy loss of RLFs. "This is due to the fact that the outdoor air and the roof temperatures reach the value of the indoor air temperature at different times respectively" (Na et al. 2014). The fall streamline patterns are shown in Figure 11. The light-bulb-on case in the fall is similar to that in the spring and summer.

The 24-h energy losses through the nine RLFs and the ceiling in each season $t$ are calculated by Eqs. (11) and (12), and the percentages of energy loss from the RLFs that are calculated by Equation (13) are summarized in Table 3. As shown in the table, the energy losses caused by the RLFs in the four seasons are all significant. In 


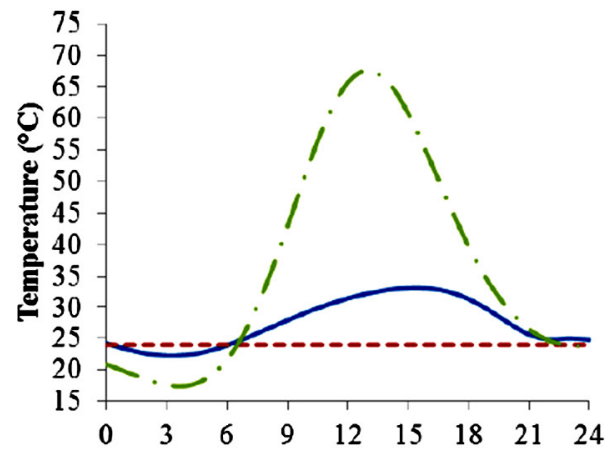

(a) Time(Hour)

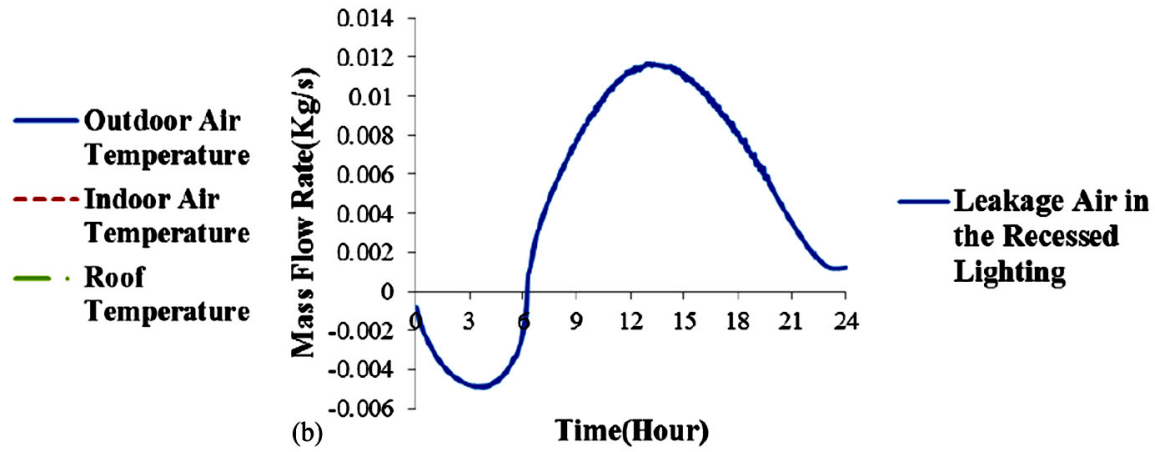

(b)

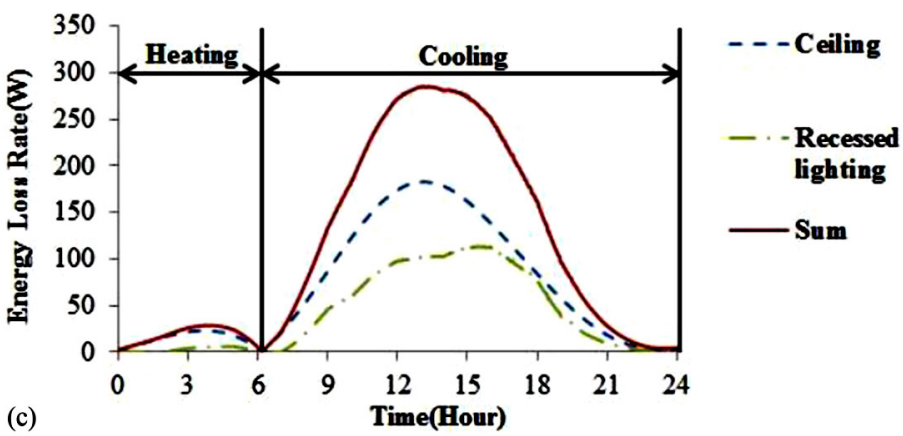

Figure 8. (a) Temperature data, (b) mass flow rate of the leakage air in recessed lighting, and (c) 24-h attic energy loss on July 10,1999

Table 3. Hourly Energy Loss from the RLFs, Total Energy Loss through the Attic, and RLF Loss Percentage

\begin{tabular}{|c|c|c|c|c|c|c|c|c|c|c|c|c|}
\hline \multirow[b]{3}{*}{$\mathrm{Hr}$} & \multicolumn{12}{|c|}{ Hourly energy loss (KJ) } \\
\hline & \multicolumn{3}{|c|}{ January 7, 1999} & \multicolumn{3}{|c|}{ April 28, 1999} & \multicolumn{3}{|c|}{ July 10, 1999} & \multicolumn{3}{|c|}{ October 29, 1999} \\
\hline & RLF & Attic & RLF\% & RLF & Attic & RLF\% & RLF & Attic & RLF\% & RLF & Attic & RLF\% \\
\hline 1 & 95.5 & 417.5 & 22.9 & 61.5 & 151.6 & 40.6 & 1.4 & 49.1 & 2.8 & 168.3 & 397.5 & 42.3 \\
\hline 2 & 104.3 & 422.7 & 24.7 & 68.9 & 168.2 & 40.9 & 9.6 & 80.2 & 11.9 & 206.2 & 454.4 & 45.4 \\
\hline 3 & 111.8 & 428.5 & 26.1 & 75.4 & 184.3 & 40.9 & 18.5 & 100.7 & 18.4 & 249.9 & 519.8 & 48.1 \\
\hline 5 & 114.2 & 431.1 & 26.5 & 79.3 & 198.2 & 40.0 & 14.6 & 55.5 & 26.3 & 294.9 & 596.1 & 49.5 \\
\hline 6 & 114.2 & 429.0 & 26.6 & 67.7 & 171.5 & 39.5 & 2.0 & 35.3 & 5.8 & 285.0 & 570.0 & 50.0 \\
\hline 7 & 122.6 & 428.4 & 28.6 & 40.5 & 101.6 & 39.9 & 33.4 & 165.7 & 20.1 & 204.4 & 416.6 & 49.1 \\
\hline 8 & 142.2 & 425.7 & 33.4 & 6.5 & 49.4 & 13.2 & 117.5 & 368.7 & 31.9 & 79.5 & 139.7 & 56.9 \\
\hline 9 & 162.2 & 404.0 & 40.2 & 44.4 & 262.3 & 16.9 & 192.2 & 570.9 & 33.7 & 62.6 & 198.8 & 31.5 \\
\hline 10 & 169.5 & 349.7 & 48.5 & 119.8 & 509.3 & 23.5 & 259.0 & 757.3 & 34.2 & 16.4 & 302.3 & 5.4 \\
\hline 15 & 136.1 & 220.5 & 61.7 & 142.9 & 472.3 & 30.3 & 406.3 & 947.2 & 42.9 & 87.3 & 343.4 & 25.4 \\
\hline 16 & 142.8 & 267.8 & 53.3 & 88.2 & 310.2 & 28.4 & 374.7 & 823.7 & 45.5 & 25.0 & 156.7 & 16.0 \\
\hline 17 & 143.2 & 297.0 & 48.2 & 41.5 & 163.3 & 25.4 & 310.9 & 661.4 & 47.0 & 30.1 & 59.6 & 50.5 \\
\hline 18 & 138.3 & 306.4 & 45.1 & 9.0 & 53.5 & 16.8 & 206.4 & 460.9 & 44.8 & 24.5 & 121.4 & 20.2 \\
\hline 19 & 135.0 & 306.9 & 44.0 & 3.2 & 13.0 & 24.3 & 107.1 & 274.2 & 39.1 & 56.4 & 213.1 & 26.5 \\
\hline 20 & 133.6 & 303.9 & 44.0 & 7.9 & 37.9 & 20.8 & 52.9 & 148.3 & 35.7 & 76.6 & 252.0 & 30.4 \\
\hline 21 & 135.8 & 302.6 & 44.9 & 13.4 & 56.7 & 23.6 & 24.2 & 69.1 & 35.0 & 81.3 & 255.5 & 31.8 \\
\hline 22 & 135.7 & 300.1 & 45.2 & 14.7 & 71.2 & 20.6 & 9.4 & 27.5 & 34.1 & 78.1 & 246.4 & 31.7 \\
\hline 23 & 132.0 & 298.2 & 44.2 & 29.3 & 107.1 & 27.3 & 4.7 & 16.1 & 29.4 & 79.9 & 250.0 & 32.0 \\
\hline Sum & $3,192.8$ & $8,048.7$ & 39.7 & 1770.2 & $5,901.8$ & 30.0 & 3616.7 & $9,684.4$ & 37.3 & $2,938.1$ & $8,335.4$ & 35.2 \\
\hline
\end{tabular}




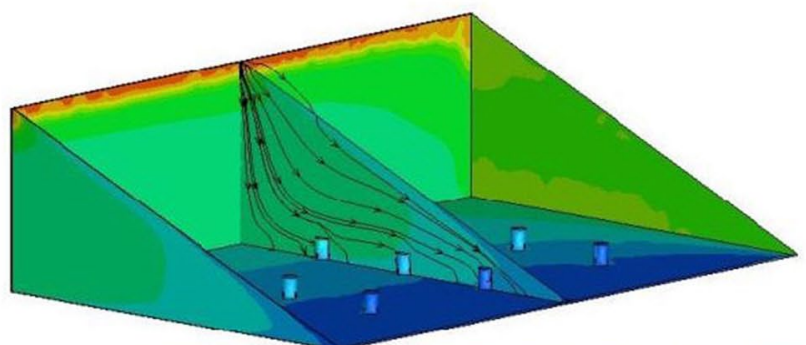

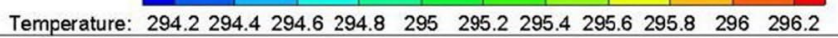

(a)

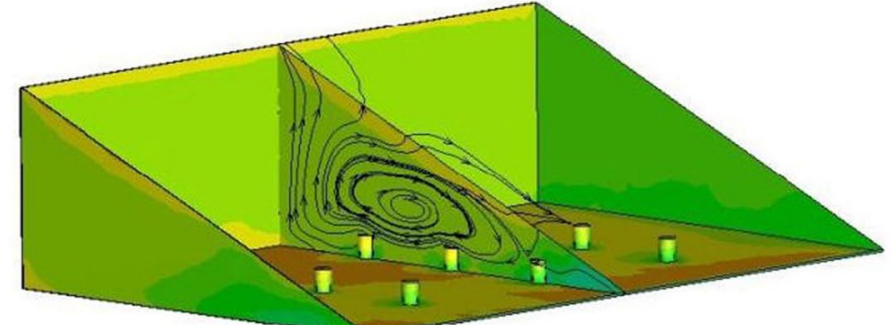

Temperature: 296298300302304306308310312314316318

(b)

Figure 9. Streamlines and contours of temperature in the (a) nighttime and (b) daytime on July 10, 1999
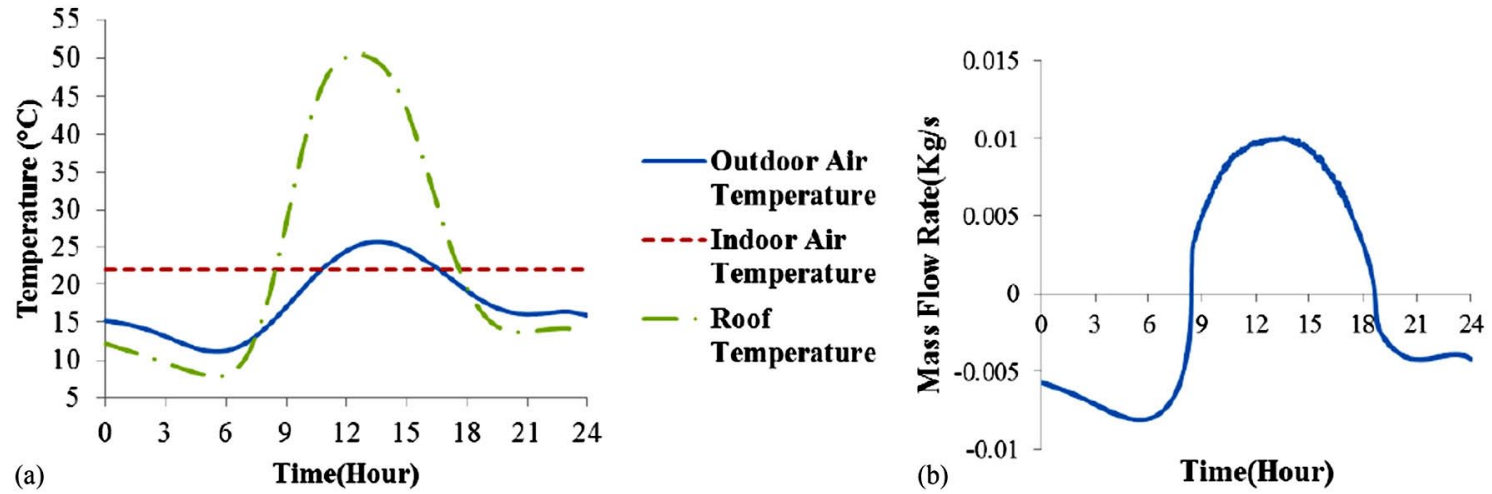

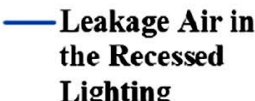

Lighting

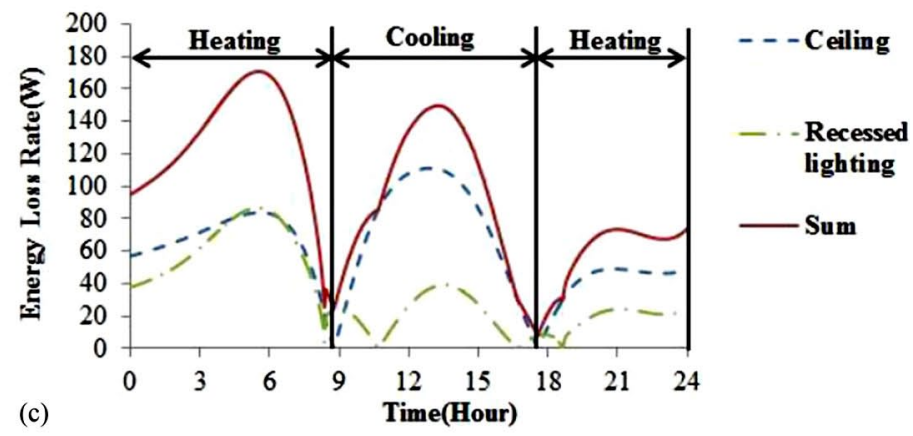

Figure 10. (a) Temperature data, (b) mass flow rate of the leakage air in recessed lighting, and (c) 24-h attic energy loss on October 29, 1999

the winter and summer, under the impacts of the energy loss from the RLFs and ceiling, the heating load and cooling load reach their highest points, respectively [Figs. 4(c) and 8(c)]. Although in the spring and fall when the climate in the mixed-humid zone is relatively moderate, the energy loss from the RLFs is still considerable. Figure 12 shows that the percentages of the energy loss from RLFs are always higher than $30 \%$ in any particular season and can reach as high as $80 \%$ in winter.

\section{Estimate of the Energy Loss from Recessed Lighting in the Mixed-Humid Zone}

Considering different climate regions and different roof/attic configurations, the energy losses per household presented in this study are estimates. Between 20 and 40 RLFs per household are used in the estimate calculations (Van der Meer 2002). Two cases are considered in the estimation. In the first case, all 20-40 RLFs are assumed on the attic ceiling, whereas in the second case, only half of the RLFs ( 10-20) are assumed on the attic ceiling. No matter which case (Table 4), the annual energy loss from RLFs cannot be ignored. Considering the large number of such homes [10.2 million units just in the mixed-humid climate zone alone according to the U.S. EIA (2009)], the RLF energy loss in the region is quite substantial.

\section{Conclusions}

In this paper, the authors presented a quantitative investigation of the RLF energy loss due to the air filtration. Even in this moderate mixed-humid climate zone, the results indicate RLFs are still a substantial source of energy loss. On the basis of these case results the authors concluded that in residential buildings with ventilated attics and attic-mounted RLFs, a significant amount of energy can be wasted through air leakage of non-IC-rated RLFs. IC-rated RLFs or LED lights could be alternative strategies to reduce energy loss. 


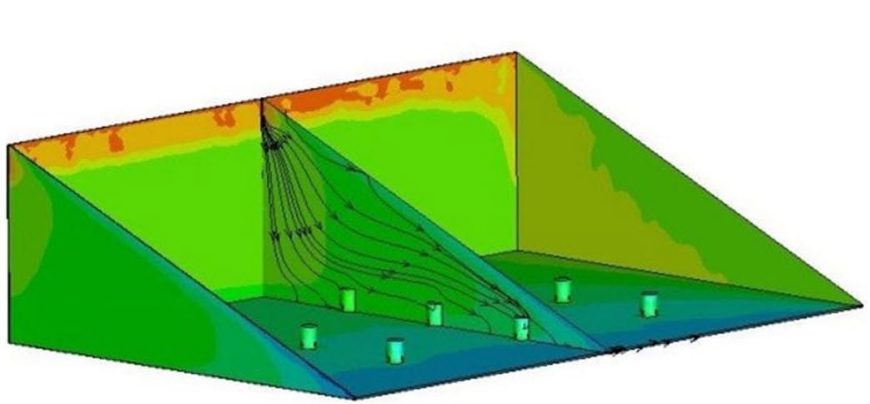

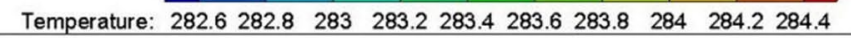

(a)

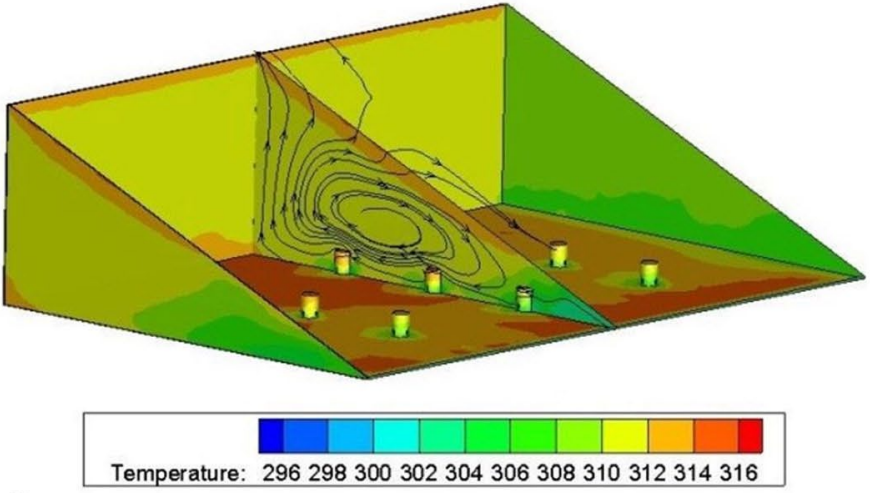

(b)

Figure 11. Streamlines and contours of temperature in the (a) nighttime and (b) daytime on October 29, 1999

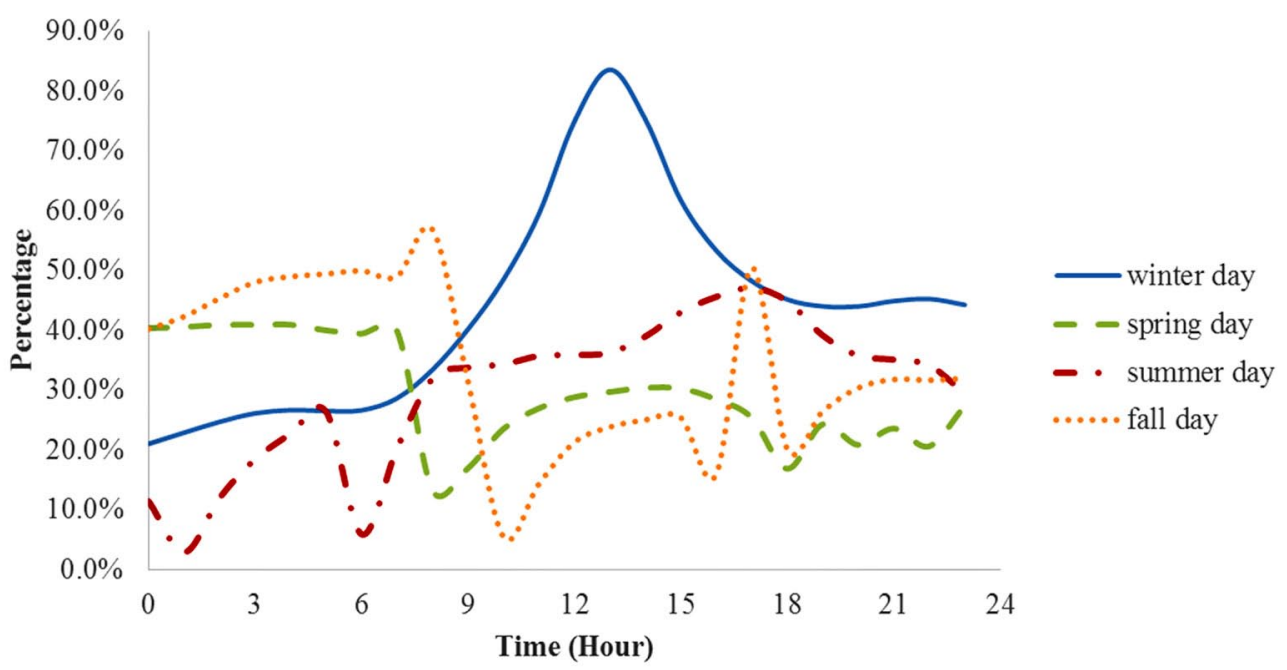

Figure 12. Percentages of energy loss from recessed lighting

Table 4. Energy Loss from Recessed Lighting per Household in the Case Study

\begin{tabular}{|c|c|c|c|c|c|c|c|}
\hline \multirow[b]{3}{*}{ Month } & \multicolumn{3}{|c|}{ 24-h energy loss } & \multicolumn{2}{|c|}{ Monthly energy loss } & \multirow{2}{*}{\multicolumn{2}{|c|}{ Seasonal energy loss }} \\
\hline & \multirow[b]{2}{*}{ Per RLF (KJ) } & \multicolumn{4}{|c|}{ Per household in the mixed-humid zone (MJ) } & & \\
\hline & & 10-20 RLFs & 20-40 RLFs & 10-20 RLFs & 20-40 RLFs & 10-20 RLFs & 20-40 RLFs \\
\hline April & 197 & $2.0-3.9$ & $3.9-7.9$ & $59.0-118.0$ & $118.0-236.0$ & $177.0-354.0$ & $354.0-708.1$ \\
\hline July & 402 & $4.0-8.0$ & $8.0-16.1$ & $120.5-241.1$ & $241.1-482.2$ & $361.6-723.3$ & $723.3-1,446.6$ \\
\hline October & 326 & $3.3-6.5$ & $6.5-13.1$ & $97.9-195.9$ & 195.9.8-391.7 & $293.8-587.6$ & $587.6-1,175.2$ \\
\hline
\end{tabular}

There are a lot of limitations in this study (such as not considering a light-on case, moisture and vapor, wind effects, and nonvented attics), which makes it only a rough estimate, but the results of the case study still provide some evidence for the significant energy waste due to the air leakage through RLFs. "The study suggests that systematic approach is needed to improve the RLF design and construction practice to reduce or remove the RLF's negative impact on energy loss of residential buildings" (Na et al. 2014).

Acknowledgments - The authors express sincere appreciation to Dr. Jerrold Winandy for providing the multiyear temperature data collected by the USDA Forest Products Lab. Dr. Winandy retired as project leader in the Engineered Composites Science Research Work Unit at the lab in 2008.

\section{Notation}

The following symbols are used in this paper:

$A=$ heat-transfer area of the surface $\left(\mathrm{m}^{2}\right)$

$a_{1}, a_{2}, a_{3}=$ constants

$b_{1}, b_{2}, b_{3}=$ constants

$C=$ constant in the fitted temperature functions

$\mathrm{C}=$ the specific heat capacity constant $(\mathrm{J} / \mathrm{kg} \cdot \mathrm{K})$

$c_{1}, c_{2}, c_{3}=$ constants

$d_{f}=$ moving coordinate velocity

$F_{i j}=$ view factor

$f_{f}{ }_{f}=$ body forces per unit volume

$f(x)=$ roof or outdoor ambient air temperatures $(K)$ 
$h_{c}=$ convective heat-transfer coefficient of the process $\left(\mathrm{W} / \mathrm{m}^{2} \cdot \mathrm{K}\right)$

$i=$ finite surface

$j$ = finite surface

$k$ = finite surface

$m=\operatorname{mass}(\mathrm{kg})$

$Q=$ energy loss from the RLFs $(J)$

$q_{\mathrm{in}, k}=$ energy flux incident on the surface from the surroundings $(\mathrm{W})$

$q_{\text {out }, k}=$ energy flux leaving the surface $k(\mathrm{~W})$

$q_{\text {out } j}=$ energy flux leaving the surface $j(\mathrm{~W})$

$q_{c}=$ heat-transfer rate of ceiling $(\mathrm{W})$

$q_{r}=$ heat-transfer rate of the RLFs (W)

$\Delta T_{1}=$ indoor and outdoor air temperature difference $(\mathrm{K})$

$\Delta T_{2}=$ temperature difference between the surface and the bulk fluid (K)

$T_{k}=$ temperature at the surface $k(\mathrm{~K})$

$\Delta t=$ duration of energy loss

$V_{m}=$ mass flow rate of air $(\mathrm{kg} / \mathrm{s})$

$v=$ fluid velocity vector

$x=$ time

$\delta_{i j}=$ Kronecker delta

$\varepsilon_{k}=$ emissivity

$\rho_{f}=$ fluid density

$\sigma=$ Boltzmann constant

$\tau_{f}=$ fluid stress tensor

\section{References}

ANSYS Fluent 13.0 [Computer software]. ANSYS, Inc., Canonsburg, PA.

Armando, L., and McCarthy, S. (2000). "A recessed can of worms." http:// www.waptac.org/data/files/Website docs/Training/Standardized Curricula/Curricula Resources/Armanda A-Recessed-Can-of-Worms. pdf (Mar. 1, 2013).

Baechler, M. C., Williamson, J. L., Gilbride, T. L., Cole, P. C., Hefty, M. G., and Love, P. M. (2010). Building America best practices series, Vol. 7.1: Guide to determining climate regions by county (No. PNNL-17211 Rev. 1), Pacific Northwest National Laboratory (PNNL), Richland, WA.

Baker, J., and Lugano, F. (1999). "A passive approach to practical climate control." Postprints of the wooden artifacts group, American Institute for Conservation of Historic and Artistic Works, Wooden Artifacts Group,Washington, DC, 34-45.

Balaras, C., and Argiriou, A. (2002). "Infrared thermography for building diagnostics." Energy Build., 34(2), 171-183.

CBSC (California Building Standard Commission). (2013). 2013 California energy code-California Code of Regulations, Title 24, Section 6.3.12, International Code Council, Washington, DC.

Duan, R., et al. (2015). "Mesh type and number for the CFD simulations of air distribution in an aircraft cabin." Numer. Heat Transfer, Part B, 67(6), 489-506.

Emmerich, S. J., McDowell, T. P., and Anis, W. (2005). "Investigation of the impact of commercial building envelope airtightness on HVAC energy use." NISTIR 7238, U.S. Department of Commerce, Technology Administration, National Institute of Standards and Technology, Washington, DC.
GEC (General Electric Company). (1984). "Incandescent lamps." Pamphlet TP-110R2, Nela Park, OH.

Home Depot. (2015). "Recessed lighting applications." http://www.homedepot.com/hdus/en US/DTCCOM/HomePage/Know How/Brand Pages/Lighting_Fans/Halo/Docs/RecessedPlanningPad.pdf (Sep. 30, 2015).

ICC (International Code Council). (2012). "International energy conservation code, section 402.4." Country Club Hills, IL.

Jokisalo, J., Kalamees, T., Kurnitski, J., Eskola, L., Jokiranta, K., and Vinha, J. (2008). "A comparison of measured and simulated air pressure conditions of a detached house in a cold climate." J. Build. Phys., 32(1), 67-89.

MATLAB [Computer software]. MathWorks, Natick, MA.

$\mathrm{Na}$, R., Lin, S., Shen, Z., and Gu, L. (2014). "Evaluating energy loss through recessed lighting fixtures (RLF) in residential buildings through a case study." Proc., 2014 Int. Conf. on Computing in Civil and Building Engineering, ASCE, Reston, VA, 1691-1698.

Persily, A. (2004). "Q and A on building security." ASHRAE J., 46(9), 20-23.

Plympton, P. C., Dagher, L., and Zwack, W. (2007). Industry stakeholder recommendations for DOE's RD\&D for increasing energy efficiency in existing homes. National Renewable Energy Laboratory,

Golden, CO. Savers, E. (2006). "Tips on saving money and energy at home." U.S. Department of Energy, Washington, DC.

SBCC (Washington State Building Code Council). (2009). "Washington state building code, section 502.4.4." Olympia, WA.

Sherman, M. H., and Dickerhoff, D. J. (1998). "Airtightness of U.S. dwellings." ASHRAE Trans., 104(2), 1359-1367.

U.S. EIA (U.S. Energy Information Administration). (2009). "Structural and geographic characteristics of U.S. homes, by climate region." http:// www.eia.gov/consumption/residential/data/2009/\#structural (Mar. 1, 2013).

Van der Meer, B. (2002). "Air leakage in recessed lighting." Builder brief, Pennsylvania Housing Research/Resource Center, University Park, PA.

Walters, D. K., and Cokljat, D. (2008). "A three-equation eddy-viscosity model for Reynolds-averaged Navier-Stokes simulations of transitional flow." J. Fluids Eng., 130(12), 121401.

Wang, S., and Shen, Z. (2012a). "Effects of roof pitch on air flow and heating load of sealed and vented attics for gable-roof residential buildings." Sustainability, 4(9), 1999-2021.

Wang, S., and Shen, Z. (2012b). "Impacts of ventilation ratio and vent balance on cooling load and air flow of naturally ventilated attics." Energies, 5(129), 3218-3232.

Wang, S., Shen, Z., and Gu, L. (2012). "Numerical simulation of buoyancydriven turbulent ventilation in attic space under winter conditions." Energy Build., 47, 360-368.

Winandy, J. E., Barnes, H. M., and Hatfield, C. A. (2000). "Roof temperature histories in matched attics in Mississippi and Wisconsin." U.S. Department of Agriculture, Forest Service, Forest Products Laboratory.

Younes, C., Shdid, C. A., and Bitsuamlak, G. (2012). "Air infiltration through building envelopes: A review." J. Build. Phys., 35(3), 267-302. 